Received: 11 March 2019, Revised: 19 March 2019

Accepted: 11 April 2019, Published: 28 April 2019

Available online at: http://e-journal.unair.ac.id/index.php/IMHSJ

\title{
PRIMIGRAVIDA MEMILIKI KECEMASAN YANG LEBIH SAAT KEHAMILAN
}

\section{WOMEN WITH PRIMIGRAVIDA EXPERIENCE MORE ANXIETY IN PREGNANCY}

\author{
Heni Hastanti ${ }^{1}$, Budiono ${ }^{2}$, Nining Febriyana ${ }^{2}$ \\ 1. Program Studi Pendidikan Bidan, Fakultas Kedokteran, Universitas \\ Airlangga Surabaya \\ 2. Fakultas Kedokteran, Universitas Airlangga \\ Alamat korespondensi: \\ Kertoharjo Gg. 11 No. 93-A Kota Pekalongan \\ Email: heni.hastanti-2017@fk.unair.ac.id
}

\begin{abstract}
Abstrak
Latar Belakang: Kecemasan merupakan salah satu gangguan jiwa yang umum terjadi pada masa kehamilan. Prevalensi kecemasan ibu hamil di negara berkembang rata-rata mencapai $20 \%$ atau lebih. Kecemasan ibu hamil berbeda-beda tergantung pada faktor yang mempengaruhi dan kemampuan ibu beradaptasi dalam menciptakan kondisi psikologis. Penelitian ini bertujuan untuk mengetahui perbedaan kejadian kecemasan ibu hamil primigravida dan multigravida. Metode: Jenis penelitian adalah analitik observasional dengan desain studi cross sectional comparative untuk membandingkan perbedaan kecemasan primigravida dan multigravida dengan kuesioner. Populasi adalah semua ibu hamil yang tercatat dan berkunjung di Puskesmas Jenggot Kota Pekalongan. Sampel dengan teknik consecutive sampling yang dibedakan menjadi dua kelompok yaitu kelompok primigravida dan multigravida. Masing-masing kelompok 43 orang dengan kriteria inklusi kehamilan tunggal, usia ibu saat hamil 20-35 tahun, kehamilan fisiologis. Penelitian ini dilakukan di Puskesmas Jenggot Kota Pekalongan pada Bulan Februari-April 2019. Analisis data dilakukan dengan teknik komparasi Mann-Whitney, Chi Square dan Independent Samples T-Test. Hasil: Karakteristik responden antara primigravida dan multigravida diketahui bahwa karakteristik yang berbeda adalah usia ibu hamil $(\mathrm{p}=0,000)$, pendidikan $(\mathrm{p}=0,009)$ dan tipe keluarga $(\mathrm{p}=0,000)$, disimpulkan bahwa ada perbedaan usia, pendidikan dan tipe keluarga. Rata-rata skor kecemasan pada ibu hamil primigravida yaitu 70,74 sedangkan pada multigravida yaitu 65,70. Hasil uji Independet Samples T-Test didapatkan nilai $\mathrm{p}$ sebesar 0,035 sehingga disimpulkan terdapat perbedaan kecemasan pada ibu hamil primigravida dan multigravida. Kesimpulan: Kecemasan pada primigravida lebih tinggi sebesar 7,67\% dibandingkan dengan multigravida berdasarkan ratarata skor kecemasan.
\end{abstract}

Kata kunci: kecemasan, primigravida, multigravida

\section{Abstract}

Background: Anxiety is one of the common mental disorders in pregnancy. The prevalence of maternal anxiety in developing countries reaches an average of $20 \%$ and more. The anxiety in pregnancy depends on the influencing factors and the ability of the mothers to adapt and create a psychological condition. Therefore, this research aims to find out the differences in the prevalence of anxiety in primigravida and multigravida pregnancy. Method: The type of this research is analytic observational study with comparative cross-sectional design and questionnaires to compare the incidence of anxiety in primigravida and multigravida. The research population was all pregnant women who visited and recorded at Jenggot Public Health Center, Pekalongan. The sample was taken with consecutive sampling technique and divided into two groups, primigravida group, and multigravida group. Each group has 43 people with inclusion criteria of a single 
pregnancy, maternal age between 20 to 35 years old, and physiological pregnancy. The research was done at Jenggot Public Health Center, Pekalongan from February to April 2019. The technique of data analysis was carried out with the comparison technique of Mann-Whitney, Chi-Square, and Independent Samples T-Test. Results: The different characteristics of the respondent between primigravida and multigravida are maternal age $(p=0.000)$, education $(p=0.009)$, and family type $(p=0.000)$. It can be concluded that there is a difference in age, education, and type of the family. The average score of maternal anxiety in primigravida pregnancy is 70.74 while in multigravida pregnancy is 65.70. The results of Independent Samples T-Test show a p-value of 0.035 meaning that there is a difference in the incidence of anxiety in between primigravida and multigravida pregnancy. Conclusion: Based on the average score of anxiety, the level of anxiety in primigravida pregnancy is higher by $7.67 \%$ than multigravida pregnancy.

Keywords: anxiety, primigravida, multigravida

\section{PENDAHULUAN}

Masalah kesehatan mental ibu secara global dianggap sebagai tantangan kesehatan masyarakat yang besar (World Health Organization, 2018). Kecemasan merupakan salah satu gangguan jiwa yang umum terjadi pada masa kehamilan (Glover, 2014). Kecemasan merupakan reaksi normal terhadap ancaman atau bahaya tetapi bisa menjadi masalah kesehatan mental jika kecemasan tersebut berlangsung terus-menerus dan mengganggu kehidupan sehari-hari (Anxiety UK, 2018). Semakin tinggi tingkat kecemasan ibu maka kadar kortisol juga akan meningkat (Kane et al., 2014). Kortisol dapat mengakibatkan resiko persalinan lama, persalinan dengan tindakan, seksio sesaria, keguguran, gangguan pertumbuhan janin, persalinan kurang bulan, berat bayi lahir rendah, resiko alergi dan sistem kekebalan menurun. (Liou, Wang, \& Cheng, 2016; Pinto et al., 2017).

Di Indonesia prevalensi kecemasan pada ibu hamil primigravida dengan cemas ringan sebesar 33,3\%, cemas sedang sebesar 6,7\% sedangkan kecemasan pada multigravida dengan cemas ringan sebesar $26,7 \%$, cemas sedang $0 \%$ (Mandagi et al., 2013) sedangkan penelitian lain menunjukkan prevalensi kecemasan ibu hamil dengan cemas ringan sebesar 43,3\%, cemas sedang 43,3\% dan cemas berat 13,4\% (Trisiani \& Hikmawati, 2016). Kecemasan ibu hamil primigravida dan multigravida berbeda-beda. Pengalaman ibu hamil, baik yang menyenangkan maupun yang menimbulkan trauma juga dapat menimbulkan gangguan kecemasan (Rukiyah \& Yulianti, 2009).

Ibu hamil multigravida sudah berpengalaman menghadapi proses persalinan dan melahirkan maka mereka lebih bisa memahami dan merasa lebih tenang. Pada primigravida, kehamilan dan persalinan merupakan hal asing bagi mereka, hal ini 
dapat menimbulkan kecemasan (Biaggi et al., 2016). Berdasarkan hal ini peneliti tertarik untuk mengetahui perbedaan kecemasan ibu hamil primigravida dan multigravida. Tujuan dari penelitian ini untuk mengetahui perbedaan kejadian kecemasan ibu hamil primigravida dan multigravida di Puskesmas Jenggot Kota Pekalongan.

\section{METODE}

Jenis penelitian ini bersifat penelitian analitik observasional dengan rancang bangun cross sectional comparative. Populasi adalah semua ibu hamil yang tercatat dan berkunjung di Puskesmas Jenggot Kota Pekalongan. Sampel penelitian ini adalah ibu hamil yang tercatat dan berkunjung di Puskesmas Jenggot Kota Pekalongan kemudian dibedakan menjadi dua kelompok yaitu kelompok primigravida dan multigravida. Masing-masing kelompok dengan kriteria inklusi dan eksklusi yang ditetapkan. Kriteria inklusi: kehamilan tunggal, usia ibu saat hamil 20-35 tahun, kehamilan fisiologis. Sampel yang diambil masing-masing kelompok adalah 43 orang dengan menggunakan teknik consecutive sampling. Variabel penelitian ini adalah kecemasan pada ibu hamil yang diukur dengan menggunakan kuesioner kecemasan kehamilan yang dibuat oleh peneliti yang sudah di uji validitas dan reliabilitas. Data yang sudah terkumpul dan diolah kemudian dianalisis menggunakan uji Mann Whitney, Chi Square dan Independent Sample T-Test dengan bantuan program SPSS for Windows versi 24.

\section{HASIL DAN PEMBAHASAN}

\section{Tabel 1. Karakteristik usia ibu hamil}

\begin{tabular}{cccc}
\hline $\begin{array}{c}\text { Karakterisktik } \\
\text { Umum } \\
\text { Responden }\end{array}$ & Primigravida & Multigravida & Nilai $\mathrm{p}$ \\
\cline { 2 - 4 } & (minimum-maksimum) & $\begin{array}{c}\text { Median } \\
\text { (minimum-maksimum) }\end{array}$ & \\
\hline Usia & $24(20-31)$ & $30(21-35)$ & 0,000 \\
\hline
\end{tabular}

Berdasarkan tabel diatas dapat diketahui bahwa usia responden primigravida yaitu 20-31 tahun sedangkan usia responden multigravida adalah 2135 tahun dengan median 30 tahun. Hasil uji statistik dengan menggunakan MannWhitney didapatkan nilai $\mathrm{p}$ sebesar 0,000 atau $\mathrm{p}<0,05$ sehingga dapat disimpulkan ada perbedaan usia pada ibu hamil primigravida dan ibu hamil multigravida. 
Hal ini menunjukkan bahwa usia muda lebih sering mengalami kecemasan. Hal ini sejalan dengan teori Deklava et al. (2015) dan Madhavanprabhakaran (2015) bahwa ibu hamil dengan usia lebih muda lebih sering mengalami kecemasan dalam kehamilan. Michaud and Fombon (dalam Mardjan, 2016) berpendapat bahwa faktor usia muda lebih mudah mengalami stres dari pada usia tua.

Namun demikian, beberapa penelitian menemukan bahwa usia yang lebih tua secara positif terkait dengan skor depresi selama kehamilan (Ali et al., 2012; Fisher et al., 2013). Tidak ada hubungan signifikan yang ditemukan dengan usia (Westerneng et al., 2017; van Heyningen et al., 2017). Sedangkan penelitian lain yang mengeksplorasi faktor sosiodemografi, seperti usia, tingkat pendidikan, status pekerjaan, pendapatan dan etnis, menunjukkan hasil samar-samar (Biaggi et al., 2016).

Usia dapat mempengaruhi psikologi seseorang, semakin tinggi usia semakin baik tingkat kematangan emosi seseorang serta kemampuan dalam menghadapi berbagai persoalan (Setyaningrum, 2013). Individu yang matang yaitu yang memiliki kematangan kepribadian sehingga akan lebih sukar mengalami gangguan akibat stres, sebab individu yang matang mempunyai daya adaptasi yang besar terhadap stressor yang timbul. Sebaliknya individu yang berkepribadian tidak matang akan bergantung dan peka terhadap rangsangan sehingga sangat mudah mengalami gangguan akibat adanya stress (Stuart dan Sundeen, 2007).

Hasil penelitian ini menunjukkan bahwa usia multigravida rata-rata memiliki usia yang lebih tua dibandingkan primigravida. Usia mempengaruhi psikologi dan kematangan kepribadian sehingga ibu hamil dengan usia yang lebih matang dapat beradaptasi dengan baik terhadap stressor yang timbul.

Pada tabel 2 penelitian menunjukkan bahwa sebagian besar ibu hamil berpendidikan rendah. Pendidikan ibu hamil primigravida lebih tinggi daripada pendidikan ibu hamil multigravida. Hasil uji statistik didapatkan nilai p sebesar 0,009 atau $\mathrm{p}<0,05$ sehingga dapat disimpulkan ada perbedaan pendidikan pada ibu hamil primigravida dan ibu hamil multigravida. Hal ini menunjukkan bahwa ibu hamil yang berpendidikan tinggi lebih sering mengalami kecemasan. 
Tabel 2. Karakteristik ibu hamil

\begin{tabular}{|c|c|c|c|c|c|c|c|}
\hline \multirow[t]{2}{*}{ Karakteristik } & \multicolumn{2}{|c|}{$\begin{array}{c}\text { Primigravida } \\
\mathrm{n}=43\end{array}$} & \multicolumn{2}{|c|}{$\begin{array}{l}\text { Multigravida } \\
\mathrm{n}=43\end{array}$} & \multicolumn{2}{|c|}{ Total } & \multirow[t]{2}{*}{ Harga $\mathrm{p}$} \\
\hline & $\mathrm{f}$ & $\%$ & $\mathrm{f}$ & $\%$ & $\mathrm{f}$ & $\%$ & \\
\hline \multicolumn{8}{|l|}{ Pendidikan } \\
\hline Rendah & 17 & 19,8 & 29 & 33,7 & 46 & 53,5 & \multirow{3}{*}{0,009} \\
\hline Menengah & 22 & 25,6 & 12 & 14 & 34 & 39,5 & \\
\hline Tinggi & 4 & 4,7 & 2 & 2,3 & 6 & 7 & \\
\hline \multicolumn{8}{|l|}{ Pekerjaan } \\
\hline Ibu Rumah Tangga & 15 & 17,4 & 23 & 26,7 & 38 & 44,2 & \multirow{2}{*}{0,082} \\
\hline Bekerja & 28 & 32,6 & 20 & 23,3 & 48 & 55,8 & \\
\hline \multicolumn{8}{|l|}{ Tipe Keluarga } \\
\hline Tinggal dengan suami & 8 & 9,3 & 24 & 27,9 & 32 & 37,2 & \multirow{3}{*}{0,000} \\
\hline Tinggal dengan suami dan mertua & 9 & 10,5 & 10 & 11,6 & 19 & 22,1 & \\
\hline $\begin{array}{l}\text { Tinggal dengan suami dan } \\
\text { orangtua kandung }\end{array}$ & 26 & 30,2 & 9 & 10,5 & 35 & 40,7 & \\
\hline \multicolumn{8}{|l|}{ Pendapatan keluarga } \\
\hline$<\mathrm{UMR}$ & 15 & 17,4 & 23 & 26,7 & 38 & 44,2 & \multirow{2}{*}{0,082} \\
\hline$>$ UMR & 28 & 32 & 20 & 23,3 & 48 & 55,8 & \\
\hline
\end{tabular}

Sejalan dengan penelitian yang dilakukan di Malawi (Stewart et al., 2014) menemukan bahwa wanita dengan pendidikan lebih tinggi akan cenderung mengalami gejala kecemasan. Menurut Deklava et al. (2015) yang melakukan penelitian tentang kecemasan ibu hamil terkait sikap dokter kandungan, menunjukkan bahwa ibu hamil berpendidikan tinggi lebih mengalami kecemasan dibandingkan dengan wanita berpendidikan rendah. Begitu juga ketika membandingkan kecemasan terkait kemungkinan persalinan induksi, menunjukkan bahwa wanita yang pendidikan tinggi lebih mengalami kecemasan dibandingkan dengan wanita berpendidikan rendah. Namun demikian, berbeda dengan penelitian lain yang menyatakan bahwa kecemasan dalam kehamilan lebih umum terjadi pada wanita dengan prestasi pendidikan yang rendah (Abuidhail and Abujilban, 2014; Abujilban et al., 2014).

Peneliti berpendapat bahwa pendidikan merupakan proses menuju kematangan intelektual, yang berpengaruh kepada wawasan dan cara berpikir seseorang. Semakin tinggi pendidikan, maka informasi yang didapat semakin banyak. Informasi yang didapat bisa juga terkait komplikasi yang mungkin terjadi dalam kehamilan, maka akan semakin takut hal tersebut akan terjadi, apalagi pada primigravida yang baru pertama kali, bayangan-bayangan akan informasi yang didapat khawatir akan terjadi pada diri sendiri. Tingkat pendidikan belum tentu dapat mengurangi kecemasan. 
Penelitian ini menunjukkan bahwa lebih dari setengah ibu hamil adalah bekerja. Ibu hamil primigravida sebagian besar adalah bekerja, sedangkan ibu hamil multigravida sebagian besar adalah ibu rumah tangga. Hasil uji statistik dengan menggunakan Chi Square didapatkan nilai $\mathrm{p}$ sebesar 0,082 atau $\mathrm{p}>0,05$ sehingga dapat disimpulkan tidak ada perbedaan status pekerjaan pada ibu hamil primigravida dan ibu hamil multigravida. Hasil analisis menunjukkan bahwa baik ibu hamil yang bekerja ataupun sebagai ibu rumah tangga bisa menimbulkan kecemasan dalam kehamilan.

Pekerjaan menunjukkan tingkat sosial ekonomi dan interaksi dengan masyarakat luas, diasumsikan informasi yang didapat juga lebih banyak. Akan tetapi risiko pekerjaan terkait paparan fisik dan psikis sehingga bisa menimbulkan kecemasan. Tekanan dan tuntutan terhadap pekerjaan juga bisa mempengaruhi psikologis ibu sehingga menimbulkan kecemasan. Sebaliknya ibu hamil yang tidak bekerja berdampak pada pendapatan keluarga yang kurang sehingga bisa menimbulkan kecemasan. Berdasarkan penelitian yang dilakukan oleh Stansfeld et al., (2003), menyatakan bahwa ibu yang mempunyai aktivitas bekerja di luar rumah mendapat pengaruh yang banyak dari teman dan berbagai informasi dari pengalaman orang lain sehingga dapat mengurangi kecemasan. Sedangkan penelitian lain mengungkapkan bahwa kecemasan dalam kehamilan juga ditemukan lebih umum pada wanita yang tidak bekerja (Rubertsson et al., 2014) dan ibu rumah tangga (Yanikkerem et al., 2013). Tidak ada perbedaan status pekerjaan pada ibu hamil primigravida dan ibu hamil multigravida, diduga ibu hamil yang bekerja karena merupakan tuntutan ekonomi keluarga yang kurang. Beberapa pekerjaan ada resiko mempengaruhi kesehatan ibu dan janin, seperti paparan fisik, kimia, beban kerja, dan kondisi penurunan fisik. Adanya faktor lain yang mempengaruhi kecemasan pada ibu hamil seperti masalah keuangan dan sosial budaya.

Penelitian menunjukkan bahwa tipe keluarga ibu hamil yang paling banyak adalah tinggal dengan suami dan orangtua kandung. Sebagian besar primigravida tinggal dengan suami dan orangtua kandung, sedangkan sebagian besar multigravida tinggal dengan suami. Hasil uji statistik dengan menggunakan Chi Square didapatkan nilai $\mathrm{p}$ sebesar 0,000 atau $\mathrm{p}<0,05$ sehingga dapat disimpulkan 
ada perbedaan tipe keluarga pada ibu hamil primigravida dan ibu hamil multigravida. Hal ini menunjukkan bahwa ibu hamil yang tinggal dengan suami dan orangtua kandung (extended family) lebih mengalami kecemasan dibandingkan dengan ibu hamil yang tinggal hanya dengan suami (nuclear family). Hasil penelitian ini menunjukkan bahwa orangtua mempunyai peranan dalam kecemasan ibu hamil. Dukungan suami dan orang tua bisa berupa dukungan secara fisik, emosional maupun informasi. Ibu hamil yang tinggal dengan orangtua akan mendapatkan rasa nyaman karena ada perhatian dan support mental. Disisi lain masyarakat di Puskesmas Jenggot, orangtua kecenderungan masih menganut adat budaya dan mitos yang harus dipatuhi, sehingga memberikan informasi yang kurang benar kepada ibu hamil primigravida. Penelitian ini sejalan dengan penelitian lain bahwa seorang wanita hidup dengan pasangan bukan prediktor yang signifikan (van Heyningen et al., 2017).

Berbeda dengan penelitian Madhavanprabhakaran et al. (2015) keluarga inti (tinggal dengan suami) lebih beresiko mengalami kecemasan dalam kehamilan. Sifat keluarga inti mendorong untuk mengurangi paparan transfer pengetahuan tradisional dari ibu ke anak dibandingkan dengan sistem keluarga besar sebelumnya. Kurangnya informasi ilmiah dan komprehensif tentang persiapan persalinan berkontribusi pada meningkatnya kekhawatiran terkait kehamilan. Meskipun wanita berpendidikan ini mencari tersedia dalam formasi melalui majalah, media dan teman-teman yang tidak komprehensif atau lengkap, justru memicu peningkatan kecemasan spesifik kehamilan mereka.

Peneliti berasumsi bahwa perbedaan ini diduga karena ibu hamil primigravida yang tinggal dengan orangtua kandung masih mempercayai adat dan mitos-mitos terkait kehamilan dan persalinan, masih menurut apa yang dikatakan orangtua. Adat/mitos yang masih melekat di Pekalongan yang dipercaya bisa mempengaruhi kehamilan dan proses persalinan. Adat dan mitor-mitos tersebut belum diketahui kebenarannya, antara percaya dan tidak, sehingga justru bisa memicu kecemasan akan akibat adat dan mitos tersebut.

Penelitian menunjukkan bahwa sebagian besar ibu hamil memiliki pendapatan keluarga $>$ UMR. Pendapatan keluarga yang $<$ UMR lebih banyak terjadi pada multigravida daripada primigravida. Hasil uji statistik dengan 
menggunakan Chi Square didapatkan nilai $p$ sebesar 0,082 atau $p>0,05$ sehingga dapat disimpulkan tidak ada perbedaan pendapatan keluarga pada ibu hamil primigravida dan ibu hamil multigravida. Hal ini menunjukkan bahwa pendapatan keluarga baik <UMR atau $>$ UMR bisa menimbulkan kecemasan. Keuangan merupakan salah satu stressor yang dapat memicu kecemasan ibu hamil. Akan tetapi pendapatan keluarga bukan merupakan alat untuk mengukur kecukupan keuangan keluarga, karena tiap keluarga memiliki kebutuhan yang berbeda-beda. Diduga tidak ada perbedaan pendapatan keluarga karena adanya asuransi Kartu Indonesia Sehat (KIS) sehingga dapat mengurangi kecemasan terkait biaya persalinan. Hal ini sejalan dengan Abuidhail and Abujilban (2014) yang menyatakan tidak ada korelasi yang signifikan antara penghasilan rendah dengan kecemasan. Berbeda dengan hasil penelitian lain yang menyatakan pendapatan yang lebih rendah memiliki kecemasan antenatal yang lebih besar (Dunkel-Schetter et al. 2016).

Dari karakteristik semua responden baik primigravida maupun multigravida, diketahui bahwa karakteristik yang berbeda adalah usia, pendidikan, tipe keluarga. Hal ini menunjukkan bahwa ibu hamil dengan usia muda, pendidikan lebih tinggi, dan tipe keluarga yang tinggal dengan orangtua cenderung mempunyai kecemasan lebih tinggi dibandingkan dengan usia lebih tua, berpendidikan rendah dan tipe keluarga inti.

\section{Tabel 3. Distribusi kecemasan pada ibu hamil}

\begin{tabular}{|c|c|c|c|c|c|}
\hline \multirow{2}{*}{ Variabel } & \multicolumn{2}{|c|}{$\begin{array}{c}\text { Primigravida } \\
n=43\end{array}$} & \multicolumn{2}{|c|}{$\begin{array}{l}\text { Multigravida } \\
n=43\end{array}$} & \multirow{2}{*}{ Nilai $p$} \\
\hline & Mean & $\mathrm{SD}$ & Mean & $\mathrm{SD}$ & \\
\hline Kecemasan pada ibu hamil & 70,74 & 9,835 & 65,70 & 11,903 & 0,035 \\
\hline
\end{tabular}

Penelitian ini diketahui bahwa rata-rata kecemasan pada ibu hamil primigravida yaitu 70,74 dengan rentang skor 47-88, sedangkan rata-rata kecemasan pada ibu hamil multigravida adalah 65,70 dengan rentang skor 42-89. Hasil uji Independet Samples T-Test didapatkan nilai p sebesar 0,035 atau p $<0,05$ sehingga dapat disimpulkan terdapat perbedaan kecemasan pada ibu hamil primigravida dan ibu hamil multigravida. Hal ini menunjukkan bahwa kecemasan pada ibu hamil primigravida lebih tinggi dibandingkan dengan kecemasan pada ibu hamil multigravida. Kecemasan ibu hamil primigravida lebih tinggi sebesar 7,67\% 
dibandingkan dengan kecemasan ibu hamil multigravida berdasarkan rata-rata kecemasan.

Penelitian ini sesuai dengan Madhavanprabhakaran et al. (2015) bahwa wanita yang belum pernah melahirkan lebih tinggi tingkat kecemasan dibandingkan dengan wanita yang pernah melahirkan, terkait kecemasan terhadap persalinan. Prevalensi yang lebih tinggi dari kecemasan dalam kehamilan terkait persalinan pada trimester ketiga yang parah dilaporkan terutama oleh wanita hamil nulipara (Rakesh et al., 2015). Sementara studi penelitian lain menemukan bahwa tidak ditemukan hubungan gravida dalam depresi antenatal (Biaggi et al., 2016). Iqbal et al. (2015) juga menyatakan tidak ada perbedaan tingkat kecemasan kelompok ibu primigravida dan multigravida. Peran graviditas dan paritas masih belum jelas, meskipun primigravida telah dikaitkan dengan depresi, tetapi tidak dengan kecemasan. Wanita dengan komplikasi kehamilan saat ini atau masa lalu atau komplikasi persalinan sebelumnya dan dengan riwayat keguguran, penghentian kehamilan atau kelahiran mati telah ditemukan lebih mungkin untuk mengalami kecemasan dalam kehamilan (Biaggi et al. 2016). Dalam penelitian yang mengendalikan faktor-faktor demografi dan sosial ekonomi, multigraviditas meningkatkan risiko diagnosis kecemasan tiga kali lipat (van Heyningen et al., 2017).

Perbedaan kecemasan pada ibu hamil primigravida dan multigravida didapatkan bahwa kecemasan primigravida lebih tinggi daripada multigravida, hal ini karena primigravida mengalami suatu hal yang baru yang belum pernah dialaimi, sehingga membutuhkan adaptasi terutama terhadap perubahan fisik dan ketidaknyamanan yang terjadi selama kehamilan. Kehamilan pertama merupakan hal yang sangat dinantikan dalam hidup dan penuh teka-teki, kebahagiaan dan pengharapan (Kaplan \& Sadock, 2010). Faktor lain yang diduga juga dikarenakan usia yang lebih muda, pengaruh informasi dan cerita dari pengalaman orang lain yang negatif. Sedangkan multigravida sudah memiliki pengalaman dalam menghadapi kehamilan dan pernah mengalami proses persalinan, sehingga cenderung lebih tidak cemas. Kecemasan yang muncul pada multigravida bisa disebabkan oleh pengalaman persalinan sebelumnya, kurang dukungan, atau masalah keuangan (Jeyanthi \& Kavitha, 2008). 


\section{SIMPULAN DAN SARAN}

Kecemasan pada ibu hamil primigravida lebih tinggi dibandingkan dengan kecemasan pada ibu hamil multigravida. Kecemasan ibu hamil primigravida lebih tinggi sebesar 7,67\% dibandingkan dengan kecemasan ibu hamil multigravida berdasarkan rata-rata kecemasan. Penelitian selanjutnya sebaiknya juga menelusuri strategi koping yang dilakukan, membedakan kecemasan pada ibu hamil yang diklasifikasikan lagi menjadi kecemasan tiap trimester 1, 2 dan 3 baik primigravida maupun multigravida sehingga lebih komprehensif.

\section{DAFTAR PUSTAKA}

Abuidhail, J., Abujilban, S. (2014). Characteristics of Jordanian Depressed Pregnant Women: A Comparison Study. J. Psychiatr. Ment. Health Nurs. 21, 573-579

Abujilban, S.K., Abuidhail, J., Al-Modallal, H., Hamaideh, S., Mosemli, O., (2014). Predictors of Antenatal Depression Among Jordanian Pregnant Women in Their Third Trimester. Health Care Women Int. 35, 200-215

Ali, N.S., Azam, I.S., Ali, B.S., Tabbusum, G., Moin, S.S. (2012). Frequency and Associated Factors for Anxiety and Depression in Pregnant Women: A Hospital-Based Cross-Sectional Study. Sci. World J. 653098.

Anxiety UK. (2018). Anxiety Conditions. [online] anxietyuk.org. Diperoleh dari: https://www.anxietyuk.org.uk/get-help/anxiety-information/ [25 September 2018]

Anxiety UK. (2018). Generalised Anxiety Disorder. [online] anxietyuk.org. Diperoleh dari: https://www.anxietyuk.org.uk/anxiety-type/generalisedanxiety-disorder/ [25 September 2018]

Biaggi, A., Conroy, S., Pawlby, S., and Pariante, C. M. (2016). Identifying the Women at Risk of Antenatal Anxiety And Depression: A Systematic Review. Journal of Affective Disorders, 191, pp. 62-77. https://doi.org/10.1016/j.jad.2015.11.014

Deklava, L., Lubina, K., Circenis, K., Sudraba, V., and Millere, I. (2015). Causes of Anxiety During Pregnancy. Procedia - Social and Behavioral Sciences, 205, pp. 623-626. https://doi.org/10.1016/j.sbspro.2015.09.097

Fisher, J., Tran, T., Duc Tran, T., Dwyer, T., Nguyen, T., Casey, G.J., Anne Simpson, J., Hanieh, S., Biggs, B.A. (2013). Prevalence and Risk Factors for Symptoms of Common Mental Disorders In Early and Late Pregnancy In Vietnamese Women: A Prospective Population-Based Study. J. Affect. Disord. 146, 213-219.

Glover, V. (2014). Maternal Depression, Anxiety and Stress During Pregnancy and Child Outcome; What Needs to Be Done. Best Practice and Research: Clinical Obstetrics and Gynaecology, 28(1), pp. 25-35. https://doi.org/10.1016/j.bpobgyn.2013.08.017

Iqbal, M., Wati, Y. R., \& Yulianti, A. B. (2015). Perbandingan Tingkat Kecemasan 
Primigravida dengan Multigravida di RSUD Majalaya. Global Medical and Health Communication, 3(2), 93-100. https://doi.org/10.1002/eji.200737187 Jeyanthi, I., Kavitha R. (2008) Anxiety and Stress Among The Primigravida and The Multigravida. Departement of Social Work, Cauvery College for Women, Trichy. 1 (2): 128.

Kane, H. S., Dunkel, C., Glynn, L. M., Hobel, C. J., and Sandman, C. A. (2014). Pregnancy Anxiety and Prenatal Cortisol Trajectories. Biological Psychology, 100, pp. 13-19. https://doi.org/10.1016/j.biopsycho.2014.04.003

Kaplan, H. I. dan Sadock, B. J. (2010) Sinopsis Psikiatri: Ilmu Pengetahuan Perilaku Psikiatri Klinis Jilid Pertama. Ed. 10. Jakarta: EGC, hlm. 1-42

Kaplan, H. I., Sadock, B. J., \& Grebb, J. A. (2010). Sinopsis Psikiatri, Jilid 2. (I. M. Wiguna, Ed.). Tangerang: Binarupa Aksara, hlm. 17-83.

Liou, S. R., Wang, P., \& Cheng, C. Y. (2016). Effects of Prenatal Maternal Mental Distress on Birth Outcomes. Women and Birth, 29(4), pp. 376-380.

Madhavanprabhakaran, G. K., D’Souza, M. S., \& Nairy, K. S. (2015). Prevalence of Pregnancy Anxiety and Associated Factors. International Journal of Africa Nursing Sciences, 3, 1-7. https://doi.org/10.1016/j.ijans.2015.06.002

Madhuri, R., Jinnah, N., Abdullah, M., \& Mistry, M. (2015). The Prevalence of Pregnancy-Specific Anxiety Across the Three Trimesters of Pregnancy, Postnatal Period and Its Relationship with Labour Outcomes. International Scholars Journals, 2(6), 187-193.

Mandagi, D. V. V, Pali, C., \& Sinolungan, J. S. V. (2013). Perbedaan Tingkat Kecemasan pada Primigravida dan Multigravida di RSIA Kasih Ibu Manado. Jurnal E-Biomedik, 1(1), 197-201.

Mardjan. (2016). Pengaruh Kecemasan Pada Kehamilan Primipara Remaja. Pontianak: Abrori Institute.

Pinto, T. M., Caldas, F., Nogueira-Silva, C., and Figueiredo, B. (2017). Maternal Depression and Anxiety and Fetal Neonatal Growth. Jornal de Pediatria, 93(5), pp. 452-459. https://doi.org/10.1016/j.jped.2016.11.005

Rubertsson C, Hellström J, Cross M, Sydsjö G. (2014) Anxiety In Early Pregnancy: Prevalence and Contributing Factors. Archives of Women's Mental Health. 17(3):221-228.

Rukiyah, A. Y., \& Yulianti, L. (2009). Asuhan Kebidanan I (Kehamilan (Pertama). Jakarta: Trans Info Media.

Rukiyah, A. Y., \& Yulianti, L. (2010). Asuhan Kebidanan IV (Patologi Kebidanan). Jakarta: Trans Info Media, hlm. 366-367.

Schetter, C. D., Saxbe, D., Cheadle, A., \& Guardino, C. (2016). Postpartum Depressive Symptoms Following Consecutive Pregnancies: Stability, Change, and Mechanisms. Clin Psychol Sci, 4(5), 909-918. https://doi.org/10.1177/2167702616644894.Postpartum

Stewart, R.C., Umar, E., Tomenson, B., Creed, F. (2014). A Cross-Sectional Study of Antenatal Depression and Associated Factors in Malawi. Arch. Womens Ment. Health, 17, 145-154.

Stuart, G. W. dan Sundeen S.J. (2007) Buku Saku Keperawatan Jiwa. Edisi 5. Jakarta: EGC

Trisiani, D., \& Hikmawati, R. (2016). Hubungan Kecemasan Ibu Hamil terhadap Kejadian Preeklampsia di RSUD Majalaya Kabupaten Bandung. Jurnal 
Ilmiah Bidan, 1(3), 14-18.

van Heyningen, T., Honikman, S., Myer, L., Onah, M. N., Field, S., and Tomlinson, M. (2017). Prevalence and Predictors of Anxiety Disorders Amongst LowIncome Pregnant Women in Urban South Africa: A Cross-sectional Study. Archives of Women's Mental Health, 20(6), pp. 765-775. https://doi.org/10.1007/s00737-017-0768-z

Westerneng, M., Witteveen, A. B., Warmelink, J. C., Spelten, E., Honig, A., \& de Cock, P. (2017). Pregnancy-Specific Anxiety and Its Association with Background Characteristics and Health-Related Behaviors in A Low-Risk Population. Comprehensive Psychiatry, 75, 6-13. https://doi.org/10.1016/j.comppsych.2017.02.002.

World Health Organization. (2018). Maternal and Child Mental Health. [online] www.who.int. Diperoleh dari: http://www.who.int/mental_health/maternalchild/maternal_mental_health/en/. [14 September 2018]

Yanikkerem, E., Ay, S., \& Piro, N. (2013). Planned and Unplanned Pregnancy: Effects on Health Practice and Depression during Pregnancy, 39(1), 180-187. https://doi.org/10.1111/j.1447-0756.2012.01958.x 